\title{
Heuristics and Cognitive Biases: Can the Group Decision-Making Avoid Them?
}

\author{
Juliana Osmani, Ph.D \\ University "Aleksandër Moisiu", Durrës, Albania
}

\section{Doi:10.5901/ajis.2016.v5n3s1p225}

\begin{abstract}
Bad decisions can be the result of occasional or cognitive errors. Occasional errors are related to information content and its validity, or may refer to errors in understanding the problem or situation. Cognitive distortions are systematic errors, repeated constantly and unconsciously. These too may be the result of errors in information interpretation or related to its reliability and accuracy. Heuristics and cognitive biases affect the different stages of the decision-making process and have negative effects on human behavior and relationships, because they are not easily identifiable and preventable. However, the use of heuristics and cognitive biases makes easier the decision-making process. The current study tries to understand and formulate some final conclusions regarding the presence of the cognitive distortions in the decision-making process, comparing the individual level to the group level. The main reason for choosing this topic is the increased use of groups to make decisions due to the dynamic, uncertain and turbulent environment, the horizontal structure, the difficulty to establish universal rules which guide the decision-making and the higher complexity. So, the aim of the current paper is to understand if the group can be a valid tool to avoid or reduce the use of heuristics and cognitive biases.
\end{abstract}

Keywords: heuristics, cognitive biases, individual decision-making, group decision-making

\section{Introduction}

Due to bounded rationality, the decision-maker often uses the heuristics. Recalling Tversky and Kahneman (1974), the heuristics comprise a set of norms and rules that make easier the decision-making process. In some situations they are useful, because help the decision-maker to understand the complex and unclear information. However, the use of heuristics may also lead to systematic decision errors which are repeated unconsciously, called cognitive biases. These stem from the decision-maker's tendency to make wrong judgments because of the cognitive processes. A cognitive process is a reasoning, an attribution of meaning, as the interpretation of a word or a complex concept. (Mariani, 2009). So, if heuristics mean the presence of critical judgments and allow rapid responses usually effective (Nisbett and Ross, 1980), cognitive biases are abstract prejudices, not based on real data and lead to bad decisions.

The question that arises is whether being member of a group accentuates or not the use and the effect of heuristics and cognitive biases. The answer to this question is precisely the objective of what is reported and discussed below, since such response becomes important in the conditions of the organizations orientation towards group decisionmaking. Among the main heuristics and cognitive biases that can influence the decision-making process, following are analyzed the overconfidence, the confirmation bias, the framing effect, the escalation of commitment, the availability, the illusion of control and the anchoring.

\section{Aim of the Study and Research Questions}

In the decision-making there are two systems of thinking. System 1 refers to the intuitive thinking, which is fast, automatic, easier and emotional. In contrast, System 2 refers to the logic thinking, which is slower, conscious and requires more commitment. In many situations, the intuitive system may be sufficient, in other cases is preferable the logical system. In fact, experience shows that executives or managers of different organizations often use the intuitive system. What should be noted is that even the most intelligent decision-maker can fail. The errors (heuristics and cognitive biases) are more likely to occur with the use of the intuitive system compared to the logical one.

The current study tries to understand and formulate some final conclusions regarding the presence of the cognitive distortions in the decision-making process, comparing the individual level to the group level. The main reason for choosing this topic is the increased use of groups to make decisions due to the dynamic, uncertain and turbulent environment, the horizontal structure, the difficulty to establish universal rules which guide the decision-making and the 
higher complexity. So, the aim of the current paper is to understand if the group can be a valid tool to avoid or reduce the use of heuristics and cognitive biases.

To support the main purpose, the research questions are as follows:

1. Are there important differences between individuals and groups regarding the use of heuristics and cognitive biases?

2. Does the group avoid or reduce the presence of cognitive distortions?

\section{Methodology}

For this paper is adopted the literature based research methodology. So, the study starts bringing a general theoretical framework of some important heuristics and cognitive biases than can affect both the individual and group decisionmaking process. It continues trying to elaborate some final conclusions in order to understand if the groups accentuate, reduce or avoid such systematic errors.

This methodology assumes importance because analyzing and discussing on the theoretical basis of cognitive distortion, individual and group decision-making, we can:

- $\quad$ find new ideas for future researches;

- define different objects of investigation;

- $\quad$ elaborate appropriate research designs with the respective objectives and hypotheses to be tested.

\section{Cognitive Distortions: Theoretical Approach}

The self-confidence is necessary to achieve the desired results and can inspire respect and confidence in others, but overconfidence can become a barrier to the effective decision-making (Bazerman and Moore, 2009). The overconfidence bias may also occur within a group, when there are members overconfident that overestimate their abilities regarding the problem or situation for which the group has to decide. The member that appears self-confident orients other group members towards the acceptance of his point of view. All this stems from the fact that this kind of decision-maker presents himself as an expert and influences the judgments of the others. Arrogance can be a sign of overconfidence, but often this bias results from the polarization of the group, when the other members accept the opinion of the most extremist member (Bazerman and Moore, 2009). The decisions made under the effect of overconfidence have a higher degree of risk, precisely because of the higher demonstrated competences. Psychological studies have shown that the human being is characterized by overconfidence (Della Vigna, 2009). Thus, the individual is prone to overestimate his performance and the results achieved regarding activities that require the skills and knowledge that he has.

Overconfidence may be present in three forms (Moore and Healy, 2007): overestimation, overplacement and overprecision. We can talk about overestimation when the individual overestimates his abilities, the performance and the level of control. When the decision-maker assesses his skills and performance as better compared to those of others is the case of overplacement. When it comes to overprecision, the individual overestimates its accuracy in reasoning and making assessments.

Often the overconfidence is perceived as synonym of excessive optimism. According to Gervais and Odean (2001), the decision-maker is optimistic if he considers that the results of an alternative will be better than they actually are. But more than optimism, overconfidence is the overestimation of the personal convictions. The decision-maker can be sure that the alternative outcomes will not be good, and in this case he is overconfident, but not optimistic. The overconfidence and excessive optimism are not the same thing, but it should be underlined that excessive optimism is one of the conditions leading to overconfidence (Gervais and Odean, 2001).

Very often during the phase of information gathering, the decision-maker may give value to the information that supports the preferred alternative and ignores the information that contrasts or casts doubt on its effectiveness (Frey, 1986). If we talk about group decision-making, often the members before the group discussion, based on the personal information they have, tend to formulate opinions about the problem for which they have to decide. During and even after the discussion they remain faithful to the preliminary information and underestimate the new information to which they are exposed. In these conditions, the decision-maker becomes subject to the confirmation effect or the cognitive distortion of the preliminary hypothesis. This kind of bias may decrease the quality of the decisions and therefore becomes important to investigate the factors and the psychological processes that make it possible, both at the stage of information gathering and processing (Fischer, Greitemeyer and Frey, 2008).

The confirmation bias may also be studied in the context of the theory of cognitive dissonance elaborated by 
Festinger (1957), since this theory emphasizes that the decision-maker tries always to be consistent with himself. So, he is always searching for plausible explanations for his inconsistencies, because they create a psychological discomfort (Amerio, Bosotti, and Amione, 1978; Larrick and Boles, 1995). For many researchers of the cognitive dissonance, it arises when the ideas and opinions of the decision-maker are very different from each other or from those of others. The question is what to do to reduce the dissonance. The dissonance can be reduced searching for information that increases the preference for the chosen alternative. But we must consider that the dissonance may arise even when the decisionmaker is forced to make a choice that does not converge with the personal point of view. On the other hand, anxiety can be defeated if the individual becomes aware of being wrong, although often for the human nature is difficult to admit that he was wrong (Jonas et al., 2001). Schulz-Hardt et al. (2000) have concluded that the confirmation bias is not present only in the post-decision phase, but can also occur during the selection phase, when the decision-maker has a strong preference for the alternative. This converges with the results of other studies according to which a distorted assessment of alternatives and information may also occur before the decision is taken (Russo, Medvec and Meloy, 1996; Boiney, Kennedy and Nye, 1997).

Tversky and Kahneman (1981) with the prospect theory were the first who highlighted the framing effect. According to this theory the decisions are influenced by how the situations are structured. Consequently, the decisions for the same situation, but that is framed or contextualized differently, may not be the same. The framing effect often defines the attitude of the decision-maker toward risk. If the situation/problem is formulated accentuating the possible positive outcomes, the decision-maker is risk-averse and tends to choose the sure option. If the problem or situation is framed in a context that are accentuated the potential losses, the individual tends to be risk-seeking.

Tversky and Kahneman (1981) with "the problem of the Asian disease" try to illustrate how different formulations of the same problem lead to different choices. The United States are preparing for a new contagious disease from Asia, where 600 people risk their lives. To understand the framing effect were composed two groups. Each group was presented two alternative programs. So, for the first group the alternatives were as follows:

- Program A: 200 people will be saved;

- Program B: there is a probability of $1 / 3$ that 600 people will be saved, and a $2 / 3$ probability that no people will be saved.

The alternative programs for the second group were:

- Program C: 400 people will die;

- Program $D$ : there is $1 / 3$ probability that nobody will die, and $2 / 3$ probability that 600 people will die.

It is evident that the programs $A$ and $B$ are equivalent respectively to $C$ and $D$ programs, but the answers were very different. The majority in the first group chose Program $A$, while the majority in the second group chose program $D$. This experiment shows that the same solutions, but presented in different ways have a different impact on the decisionmaking process. Thus, although in conditions of equivalent options, when the alternatives are formulated in positive or gain terms is chosen the certain options, but when the results are formulated in terms of losses is preferred the risky alternative (Bazerman and Moore, 2009).

Empirical studies have shown that the psychological mechanisms of framing depend on different social and cognitive variables. An important role can assume the information that the decision- maker has (Levin, Scheider and Gaeth, 1998) or the justification required of a choice (Miller and Fagley, 1991). The framing effect can be manifested in three forms (Schneider, Levin and Gaeth, 1995; Levin, Scheider and Gaeth, 1998). So, we have the risky choice framing that affects the attitude of the decision-maker toward risk. This form of framing is the form most closely associated with the term "framing". Another form is the attribute framing, in which some characteristic of an object or event serves as the focus of the framing manipulation. A third type is the goal framing, in which the goal of an action or behavior is framed.

Table 1: Types of framing

$\begin{array}{lll}\text { Frame type } & \text { What is framed } & \text { What is affected } \\ \text { Risky choice } & \text { Set of options with different risk levels } & \text { Risk preference } \\ \text { Attribute } & \text { Object/event attributes or characteristics } & \text { Item evaluation } \\ \text { Goal } & \text { Consequence or implied goal of a behavior } & \text { Impact of persuasion }\end{array}$

Source: Levin, Scheider and Gaeth, 1998, p.151

The bias of escalation of commitment refers to the tendency of insisting with ineffective decisions, even when it is impossible that the negative outcomes become positive. This is a cognitive bias widely studied by Staw (1981). In a 
research conducted on American organizations he came to the conclusion that for the most of them it was possible to close the divisions which for years operated in loss after the responsible managers of the investments left their respective companies.

The conditions that favor the escalation of commitment may be different (Bazerman and Moore, 2009). Often, the favorable conditions may result from the framing effect. As discussed above, if the situations are framed in a positive way the decision-maker is risk-averse, but if they are framed in a negative way, he becomes risk-seeking and falls into the trap of escalation. Another cause can be the confirmation bias. So, if the decision-maker does not take into account the information regarding the negative consequences of the decision, he continues with the escalation. It can also be a cause the bias of illusion of control, especially in the cases of long-term investments, pushing the decision-makers to continue until the end, interpreting the unexpected obstacles and results as temporary and controllable. The escalation of commitment can also be a consequence of loss aversion and effect of expectations (Mariani, 2009). Kahneman and Tversky (1979) have shown that the individual gives more weight to a loss than to a gain in a scale 2.5 to 1 . So, to compensate a loss of $€ 1.000$ is needed a gain of $€ 2.500$. According to the effect of expectations, the decision-maker evaluates the results of its decision referring to expectations and not to the initial situation (Mariani, 2009). If he expects to earn $€ 10.000$ and gains only $€ 7.000$, the decision-maker perceives a loss of $€ 3.000$ instead of a gain of $€ 7.000$, and according to the bias of loss aversion, to compensate such loss he ought to gain $€ 7.500$.

Some researches to explain the escalation of commitment focus on the individual causes. Referring to the theory of self-justification of White (1993), when the individuals responsible for a project identify themselves with it, they continue to persist with the project demonstrating confidence in their decision-making skills, taking into account only the positive information and trying to justify the decisions made. We must emphasize that an individual remains faithful to the initial decision also to convey a good image of him. It is clear that turning back on the decisions made is an admission of failure, a difficult behavior to be faced within the organization. The decision-maker tends to save the face in the eyes of others, so it is more dangerous a loss of identity than a loss of money (Mariani, 2009, p.20)

Often happens that the decision-maker searches for links between the current problem/situation and problems/situations of the past. After he finds this correlation, the decision-maker tends to choose an option that is similar to the decision made in the past. The heuristic of availability occurs when we try to make judgments about a problem based on the presence or not of the problem in our memory (Tversky and Kahneman, 1973). The past decisions that were full of emotions and more specific will be more available compared to the decisions without emotions or that are remembered vaguely (Bazerman and Moore, 2009). This heuristic has been illustrated with an experiment by Tverksy and Kahneman (1973) on the causes of death. The individuals had to assess whether it was increased the number of deaths by murder or suicide. Most of the participants chose the option of murder, because is more present in their mind, due to the higher weight that has in the media (Mariani, 2009). Moreover, the negative events are remembered more easily (Rozin and Royzman, 2001; Baumeister et al., 2001). Another interesting experiment conducted by Tversky and Kahneman (1973) consisted on asking the participants if in the English language are more common the words that start with the letter "k", or words that have the letter "k" at third place. The majority of them answered that they are more frequently the words beginning with " $\mathrm{k}$ ", when in fact there are not. The responses of participants depended on the fact that it is much easier to recover from the memory words beginning with " $\mathrm{k}$ " rather than words which have the letter " $\mathrm{k}$ " in the third position.

The use of availability heuristic can facilitate the decision-making process in certain situations, or when a probabilistic assessment is needed. The availability heuristic may be a useful decision-making strategy, since our minds generally recall the frequent events more easily than rare events (Bazerman and Moore, 2009, p.7). However, not always the use of this heuristic leads to good decisions. It may be that a past event is easily remembered, but the information related to it is not so relevant to the current decision. The presence of a situation in the memory leads the decision-maker to consider different situations as similar and so it tends to decide in the same way. Another explanation could be found in the phenomenon of illusory correlation of Chapman and Chapman (1969). It can happen that different events take place at the same time, but that does not mean they are related. So, we must consider all the characteristics of the events and not only those that lead to think that the events are similar. It may be that two or more problems are similar, but may have changed the contextual factors.

The cognitive distortion of illusion of control derives from the tendency of individuals or groups to believe that they have under control a problem or situation (Langer, 1975). Often the decision-maker is convinced that the negative consequences of the problems can be controlled due to its abilities. This is certainly overconfidence, since the factors that influence the decision-making process are different and the decision-maker is a human being unable to control everything. Under the influence of such bias, managers even when they are aware of the existence of a problem, do not 
worry and do nothing, overestimating their capabilities in controlling the problem (Jones and George, 2008). Everything is justified by the belief that everything is under control and there is no need to do anything, because the problem cannot degenerate. The illusion of control may result also from the positivity bias. According to the positivity, the decision-maker tends to see himself, what surrounds him and the future in an optimistic way (Bazerman and Moore, 2009).

The anchoring bias occurs under conditions of uncertainty and ambiguity, in order to help the making of judgments on the basis of reference points, which serve as anchors. Often, when the decision-maker has to make numerical estimations tends to cling to some value and then adjust the evaluations (Mariani, 2009). This is because when is requested an exact numerical answer on a problem that the individual does not know perfectly, he tends to use any number as a starting point of his evaluation. The anchoring heuristic may also derive from the confirmation effect. Thus, the decision-makers are committed in searching for confirmations of their initial assumptions. This way of acting can be useful because, like the other heuristics, it makes easier the decision-making, but can also lead to serious decision errors, especially in fields like finance. Financial decisions are made based on numerical evaluations.

To understand the consequences of this heuristic, Tversky and Kahneman (1974) requested to participants to assess the percentage of the African countries in the United Nations, asking if the number is less or greater than a completely arbitrary value between 1 and 100 that was generated by a graduated wheel. The results were amazing. When in the wheel went out the number 10, the interviewees answered $25 \%$ of African countries, and when in the wheel came out the number 65 the participants answered $45 \%$ of African countries. These results led to the conclusion that the number that came out on the wheel had influenced the estimates, because it anchored them. Epley and Gilovich (2006) report two types of anchor. In experiments such as that related to African nations represented at the United Nations, people believe that the anchor is the right answer and become subjects of the confirmation effect. So, they try to find information that confirms the anchor rather than information that deny it. When it is not given to them any anchor, the individuals generate it themselves.

\section{Individual Decision-Making vs. Group Decision-Making: Discussion and Results}

Regarding the overconfidence bias the question that arises is whether this cognitive distortion refers to the individual decision-making process or can also occur in the group decision-making. To this question we cannot answer definitively. It seems that overconfidence is characteristic for the individual. However, it can also occur in the group decision-making. This can happen when the group uses only the information that the members have, and does not gather other information from the outside, or when the members search for information outside the group in order to confirm the initial point of view. So, the overconfidence within the group may be a result of the shared information bias (Schulz-Hardt et al., 2000), or confirmation effect (Stasser, 1992; Soll and Klayman, 2004). Moreover, such distortion can occur even when the group is composed of members who have worked previously with each other and have had more successes than failures referring to the decision-making. In this context, an important role assumes the experience. The more experience the members have, the more they will be affected by overconfidence. However, regarding this we may object because as within a group there are more points of view, more criticism and counterarguments, it can be considered a useful tool to avoid overconfidence.

Discussing about the confirmation effect, some authors focus on the negative consequences of this cognitive distortion (Janis, 1982; Nemeth and Rogers, 1996). In the group decision-making process the confirmation bias occurs more than in the individual decision-making process (Frey, 1986). It is investigated as the anticipation of a group discussion, where participants expect to be part of a minority or majority, influences the information gathering. So, there is a tendency to not consider the conflicting information with the preferred alternative when the member of the group is expected to be the only one in minority during the discussion (Levine and Russo, 1995). Other studies have shown that the more the members of the group are accepted by others, the more they refer only to the information that supports their preferred alternative (Zdaniuk and Levine, 1996).

Larson, Christensen, Franz and Abbott (1998) referring to the information gathering and processing have shown that the groups during the debates make reference to the information that members possessed before the discussions, and so fail in data collection and processing that only one or few members of the group have access. Within a group the confirmation effect can also be emphasized by groupthinkin (Janis, 1982). But this has never been demonstrated by experiments or case studies (Esser, 1998). Another condition that favors the confirmation effect may also be the polarization. Vinokur and Burnstein (1978) showed that the attitudes and the individual opinions tend to polarize in homogeneous groups, while the depolarization occurs in heterogeneous groups. The confirmation effect is stronger within groups where members have an individual preference for the same alternative. The higher the diversity of individual 
preferences of the group members, the less is the dependence from the information shared (Brodbeck et al., 2002). As Mariani (2009) argues, other conditions which favor the confirmation effect can be the higher costs and the limited time that accompany the group decision-making process. Other authors think differently. Groups can reduce the confirmation effect because they can put together more knowledge, can gather more information and group members can highlight several others errors regarding the information processing (Huber, 1980).

Referring to the framing effect within a group we must underline that the conclusions of the different researches are contradictory. Neale, Bazerman, Northcraft and Alperson (1986) studied the influence of framing for individual and group risky choices. Their results confirmed the framing effect for individual decision-making, but they found a reduced framing effect in the group decision-making. Milch, Weber, Appelt, Handgraaf and Krantz (2009) found the framing effect for individual decision-making, but did not found it in the group decision-making process. Paese, Bieser and Tubbs (1993) have tried to study the same thing, but with different results. The framing effect was present in individual decisions, but was increased in the decision-making of homogeneous groups. More recently, Yaniv (2011) concluded that in homogeneous groups the framing effect is amplified, while in heterogeneous groups is reduced to zero.

White (1993) studied the escalation of commitment also at group level. To the participants were presented two projects, one with a sunk cost, the other not. Only $29 \%$ of the decision-makers who have received the description without sunk costs recommended the pursuit of the project. When the description includes sunk costs, $69 \%$ of the decision-makers preferred it as a project. But what happens at the group level? Only $26 \%$ of the groups recommended the project without sunk costs, while $86 \%$ recommended the project with sunk costs. Thus, the author argues that the escalation of commitment is higher when the decision is made by a group compared to the individual level. We may think that in the group decisionmaking, the escalation of commitment can be avoided, because sooner or later someone of the members will understand that the decision is not effective. Thus, the empirical evidences of Bazerman, Giuliano and Appelman (1984) have shown that groups fall less into the escalation of commitment, but if it happens this bias is more pronounced than at the individual level. Groups should exhibit escalation patterns similar to individuals to the extent that the group as a unit experiences dissonance (p.143). On the other hand, we must not forget that the group may be subject of the groupthinkin phenomenon. In this case, the members of the group will continue to support the initial decision, accentuating the escalation of commitment.

About the presence of the availability heuristic in the group decision-making, there are no researches to our knowledge that have compared the group and the individual level of decision-making. However, we believe that we must consider the experience of the members. The higher the experience of the group members regarding the decisionmaking, the greater is the tendency of the group to use the cognitive distortion of availability and to refer to the decisions made in the past.

Talking about the bias of illusion of control, it may be a result of overconfidence or vice versa (Moore and Healey, 2007). So, it can affect both the individual and group decision-making. Malmendier and Tate (2005) found that CEOs and top management are generally overconfident. As a result, we may think that the strategic level has the tendency to overestimate the ability of control and because of time limitations and the work volume does not base in deep analysis. According to this, it can be assumed that the illusion of control is manifested more in strategic decisions. On the other hand, perhaps in the group decision-making processes this distortion is more accentuated compared to individual processes, due to the distribution of responsibility between the members.

Let us now stop on the anchoring heuristic. With regard to group decision-making we can draw some conclusions. As reported above, the anchor stems from the confirmation effect (Epley and Gilovich, 2006). While groups are more affected by this cognitive distortion, then they should be suffering more the anchoring. Empirical evidences of Meub and Proeger (2014) offer interesting results. The authors have focused in three different domains: the knowledge of the facts, the assessment of probabilities and price evaluation. It was found that the groups are able to reduce, but not eliminate, the anchoring for decisions that require a greater knowledge of the facts. No differences were found between individuals and groups in the remaining domains.

\section{Conclusions}

The use of heuristics and cognitive biases makes easier the decision-making process. Cognitive distortions become important because more and more the decision-maker has to face new problems or situations, often unclear and ought to conclude in the conditions of absence of information or at least of minimal information.

The current research, besides analyzing the main cognitive distortions, stops to discuss about their presence in the individual and group decision-making process, in a comparative analysis. Referring to the research questions we can say that there are important differences between the individual and the group regarding the use of cognitive distortions. We 
must emphasize that the results of previous researches are often contradictory, so it becomes impossible to determine whether the group is able or not to avoid or minimize the presence of heuristics and cognitive biases. This is because, as some previous evidences suggest, the characteristics of the group (type, composition, etc.) influence the use and effects of cognitive distortions.

\section{References}

Amerio P., Bosotti E., Amione F. (1978), La dissonanza cognitiva, Torino: Bollati Boringhieri

Baumeister R.F., Bratslavsky E., Finkenauer C., Vohs K.D. (2001), Bad is stronger than good, Review of General Psychology, Vol. 5, No. 4, p. 323-370

Bazerman M.H., Moore D.A. (2009), Judgment in managerial decision making, $7^{\text {th }}$ edition, New York: John Wiley \& Sons, Inc.

Bazerman M.H., Giuliano T., Appelman A. (1984), Escalation of commitment in individual and group decision making. In Shapira Z. (2002), Organizational Decision Making, Cambridge University Press

Boiney L.G., Kennedy J., Nye P. (1997), Instrumental bias in motivated reasoning: More when more is needed, Organizational Behavior and Human Decision Processes, Vol. 72, No. 1, p. 1-24

Brodbeck F.C., Kerschreiter R., Mojzisch A., Frey D., Schulz-Hardt S. (2002), The dissemination of critical, unshared information in decision making groups: The effects of pre-discussion dissent, European Journal of Social Psychology, Vol. 32, p. 35-56

Chapman L.J., Chapman J.P. (1969), Illusory correlation as an obstacle to the use of valid psycho-diagnostic signs, Journal of Abnormal Psychology, Vol. 74, No. 3, p. 271-280

Della Vigna S. (2009), Psychology and economics: Evidence from the field, Journal of Economic Literature, Vol. 47, No. 2, p. 315-372

Epley N., Gilovich T. (2006), The anchoring and adjustment heuristic: Why the adjustments are insufficient, Psychological Science, Vol. 17, No. 4, p. 311-318

Esser J.K. (1998), Alive and well after 25 years: A review of groupthink research, Organizational Behavior and Human Decision Processes, Vol. 73, p. 116-141

Festinger L. (1957), A theory of cognitive dissonance, Stanford, CA: Stanford University Press

Fischer P., Greitemeyer T., Frey D. (2008), Self-regulation and selective exposure: The impact of depleted self-regulation resources on confirmatory information processing, Journal of Personality and Social Psychology, Vol. 94, No. 3, p. 382-395

Frey D. (1986), Recent research on selective exposure to information. In Berkowitz L. (Eds.) Advances in experimental social psychology, Vol. 19, p. 41-80, New York: Academic Press

Gervais S., Odean T. (2001), Learning to be overconfident, The Review of Financial Studies, Vol. 14, No. 1, p. 1-27

Huber G.P. (1980), Managerial decision making, Glenview, IL: Scott, Foresman and Co

Janis I.L. (1982), Groupthink: Psychological studies of policy decisions and fiascoes, $2^{\text {nd }}$ ed., Boston: Houghton Mifflin

Jonas E., Schulz-Hardt S., Frey D., Thelen N. (2001), Confirmation bias in sequential information search after preliminary decisions: An expansion of dissonance theoretical research on selective exposure to information, Journal of Personality and Social Psychology, Vol. 80, No. 4, p. 557-571

Jones G.R., George J.M. (2008), Contemporary management, Boston: McGraw-Hill/Irwin, $5^{\text {th }}$ Edition

Kahneman D., Tversky A. (1979), Prospect theory: An analysis of decision under risk, Econometrica, Vol. 47, No. 2, p. 263-291

Langer E.J. (1975), The illusion of control, Journal of Personality and Social Psychology, Vol. 32, No. 2, p. 311-328

Larrick R.P., Boles T.L. (1995), Avoiding regret in decisions with feedback: A negotiation example, Organizational Behavior and Human Decisions Processes, Vol. 63, No. 1, p. 87-97

Larson J.R., Christensen C., Franz T.M., Abbott A.S. (1998), Diagnosing groups: The pooling, management, and impact of shared and unshared case information in team-based medical decision-making, Journal of Personality and Social Psychology, Vol. 75, p. 9310

Levin I.P., Scheider S.L., Gaeth G.J. (1998), All frames are not created equal: A typology and critical analysis of framing effects, Organizational Behavior and Human Decision Processes, Vol. 76, No. 2, p. 149-188

Levine J.M., Russo E. (1995), Impact of anticipated interaction on information acquisition, Social Cognition, Vol. 13, No. 3, p. $293-317$

Malmendier U., Tate G. (2005), Does overconfidence affect corporate investment? CEO overconfidence measures revisited, European Financial Management, Vol. 11, No. 5, p. 649-659

Mariani M. (2009), Decidere e negoziare, II Sole 24 ORE, Milano

Meub L., Proeger T. (2014), An experimental study on social anchoring, Center for European Governance and Economic Development, Discussion Paper No. 196-March. Available at: http://ssrn.com/abstract=2410155

Milch K.F., Weber E.U., Appelt K.C., Handgraaf M.J.J., Krantz D.H. (2009), From individual preference construction to group decisions: Framing effects and group processes, Organizational Behavior and Human Decision Processes, Vol. 108, No. 2, p. $242-255$

Miller P.M, Fagley N.S. (1991), The effects of framing, problem variations and providing rationale on choice, Personality and Social Psychology Bulletin, Vol. 17, No. 5, p. 517-522

Moore D.A., Healey P.J. (2007), The trouble with overconfidence, Carnegie Mellon University. Available at: http://repository.cmu.edu/tepper

Neale M.A., Bazerman M.H., Northcraft G.B., Alperson C. (1986), Choice shift effects in group decisions: A decision bias perspective, International Journal of Small Groups Research, Vol. 2, No. 1, p. 33-42 
Nemeth C., Rogers J. (1996), Dissent and the search for information, British Journal of Social Psychology, Vol. 35, Issue 1, p. 67-76

Nisbett R., Ross L. (1980), Human inference: Strategies and short-comings of social judgment, Englewood Cliffs, New Jersey: PrenticeHall

Paese P.W., Bieser M., Tubbs M.E. (1993), Framing effects and choice shifts in group decision making, Organizational Behavior and Human Decision Processes, Vol. 56, No. 1, p. 149-165

Rozin P., Royzman E.B. (2001), Negativity bias, negativity dominance and contagion, Personality and Social Psychology Review, Vol. 5 , No. 4 , p. $296-320$

Russo J.E., Medvec V.H., Meloy M.G. (1996), The distortion of information during decisions, Organizational Behavior and Human Decision Processes, Vol. 66, No. 1, p. 102-110

Schneider S.L., Levin I.P., Gaeth G.J. (1995), The three faces of framing: risk preference, evaluation and persuasion. Paper presented at the $36^{\text {th }}$ annual meeting of the Psychonomic Society, Los Angeles, CA

Schulz-Hardt S., Frey D., Lüthgense C., Moscovici S. (2000), Biased information search in group decision making, Journal of Personality and Social Psychology, Vol. 78, No. 4, p. 655-669

Soll J.B., Klayman J. (2004), Overconfidence in interval estimates, Journal of Experimental Psychology: Learning, Memory and Cognition, Vol. 30, No. 2, p. 299-314

Stasser G. (1992), Pooling of unshared information during group discussion. In Wittenbaum G.M., Hollingshead A.B., Botero I.C. (2004), From cooperative to motivated information sharing in groups: moving beyond the hidden profile paradigm, Communication Monographs, Vol. 71, No. 3, p. 286-310

Staw B.M. (1981), The escalation of commitment to a course of action, Academy of Management Review, Vol. 6, No. 4, p. 577-587

Tversky A., Kahneman D. (1973), Availability: A heuristic for judging frequency and probability, Cognitive Psychology, Vol. 5, No. 2, p. 207-232

Tversky A., Kahneman T. (1974), Judgment under uncertainty: Heuristics and biases, Science, Vol. 185, No. 4157, p. 1124-1131

Tversky A., Kahneman D. (1981), The framing of decisions and the psychology of choice, Science, Vol. 211, No. 4481, p. 453-458

Vinokur A., Burnstein E. (1978), Depolarization of attitudes in groups, Journal of Personality and Social Psychology, Vol. 36, No. 8, p. $872-885$

White G. (1993), Escalating commitment in individual and group decision making: A prospect theory approach, Organizational Behavior and Human Decision Processes, Vol. 54, No. 3, p. 430-455

Yaniv I. (2011), Group diversity and decision quality: Amplification and attenuation of the framing effect, International Journal of Forecasting, Vol. 27, p. $41-49$

Zdaniuk B., Levine J.M. (1996), Anticipated interaction and thought generation: The role of faction size, British Journal of Social Psychology, Vol. 35, Issue 1, p. 201-218 